\section{Adam Sharp}

is managing director of

CleverTouch, a marketing automation consultancy that partners with over 300 of the most advanced and sophisticated users of marketing automation.

Keywords: marketing technology, business-to-business marketing, content strategy

\section{Technology the next skillset}

\section{Content keeps us busy}

\section{Content $\neq$ strategy}

Adam Sharp

CleverTouch, The Old Forge, The Dean, Alresford SO24 9BH, UK Tel: +44 (0)1962 67000

E-mail: asharp@clever-touch.com

\section{Content or technology? Technology every time}

\author{
Adam Sharp
}

Received (in revised form): 8th April 2015

\begin{abstract}
Marketers have been focusing on outputs that deliver an immediate impact, such as content and creative. But if marketing wants to take its rightful place at the boardroom table, it needs to look seriously at the impact it can have on the organization's technology. This article considers where the focus for marketers should be placed within the realm of IT. Journal of Direct, Data and Digital Marketing Practice (2015) 16, 255-259. doi:10.1057/dddmp.2015.28
\end{abstract}

\section{The changing demands on marketers}

Want a brutal truth? Forget your content strategy and your marketing strategy - your career will be judged on the technology infrastructure you put in place, not the content you create. Let's be honest, buying and implementing technology is not a natural skillset of most marketers, but in the next 3-5 years it will become a fundamental skillset of all senior marketers. In fact, we are already seeing experienced marketers on their third or fourth wave of technology acquisition and integration.

Technology is more important than content - every time.

As marketers, we like change, we like creative people, creative things, and we crave instant results - we have to, as we have so many plates to spin. This is one of the reasons so many marketers get lost in developing a content strategy. It is fun, it uses creative designers, needs budget, and it keeps the average marketer busy. But it is frankly rather old school and, most of the time, pretty ineffective.

Don't get me wrong, I think organizational and product positioning are essential and fundamental to every strategy. It is just that too many marketers confuse positioning with a content strategy and spew out ludicrous amounts of the stuff, all the while forgetting one fundamental point - that content is a tactic to reinforce positioning, not a strategy in itself.

\section{So, why is technology so critical to you?}

Put simply, over the next three to five years, your careers will not be measured by the branding guidelines you put in place, or by the thought leadership position and content strategy that you put in place. Nor will you be rewarded for the cool creative and the results of the last integrated 


\section{An antenna to the marketplace}

\section{Fifty-seven per cent of buying happens before sales}

\section{From ROI to marketing forecasting}

campaign, delivered in five languages. Instead, you will be measured by whether you have put a coherent technology in place that:

1. enables your business to communicate and engage your audiences in new ways;

2. provides your chief executive officer (CEO) and the leadership team with a new level of insight;

3. drives a new business model - one that supports the buyer's engagement model and a small, but smarter consultative sales force with account-based intelligence.

Let me explain why - insight can take marketing from the backroom to the boardroom. From the CEO's perspective, he or she wants the modern marketer to translate what all this new technology can do for the business in a way that the IT function simply cannot. While the IT function talks in bits and bytes, the CEO thinks marketing should be adept at providing, or at least able to provide, an antenna to the marketplace. The CEO wants marketing to talk about business outcomes based on customer and prospect insight and intelligence, in the same way the IT function can only talk about applications and data and process flows.

Despite what CEOs want, according to Forrester Research, ${ }^{1}$ only 8 per cent of CEOs currently rely on marketing data for their insight and decision making (see Figure 1). Surely, as a marketer, you want to be a driver of new ideas and of change inside the business. After all, isn't that why we all went into marketing in the first place?

Marketing technology presents an opportunity for marketers to turn this around and to prove their value in a way no content creative could ever hope for. In 2013, the world of B2B marketing was shaken by research coming out of Google/CEB that suggested that as much as 57 per cent of the buying process happens before a sales team is even aware that such a buying process is happening. ${ }^{2}$ This research highlights a fundamental shift going on in every buyer-seller relationship as it means that marketing should now seek to take responsibility for more than half of the sales funnel, instead of just the awareness phase.

Marketing automation vendors (such as Oracle's Eloqua, Marketo or Salesforce's Pardot) can help the marketer to track the 'digital body language' of these previously unknown users and help to nurture them through the funnel to revenue. This means that marketers, at the very least, can easily track the source of lead. Better still, they can work out

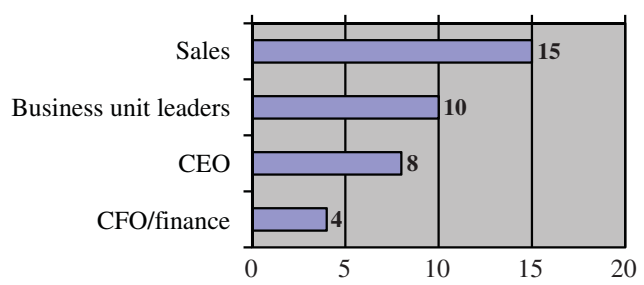

Figure 1: Functions that rely on marketing data to make decisions Source: Forrester

Note: Forrester: Only 8 per cent of CEOs rely on marketing data 


\section{Re-evaluate the broken model}

\section{Sales involved too early}

\section{A new, integrated technology}

attribution metrics and return on investment (ROI). The very smartest marketers (those with the technology infrastructure in place) can go one step further - they can forecast marketing's contribution to the business in the same way that sales can, only further out. All of a sudden, the marketer is the voice the CEO will most listen to.

The implication of this should be for organizations to re-evaluate the roles of both sales and of marketing. Too many organizations are still working to the old sales and marketing model (see Figure 2), which is broken and where marketing is over-focused on awareness, thought leadership and over-communicating to the unintended or uninterested.

Worse still, the organization is over-encumbered with an expensive sales function that is asked to pick up the relationship with prospects too early into the buying cycle, while either ignoring or passing over existing customers to 'farmers' before they are truly embedded. A truly customerfocused business needs more marketing and less sales - Figure 3 highlights just how diametrically opposed most company-oriented and customer-focused buying cycles typically are. Through most of the buying cycle, customers and prospects want a relationship with marketing and not with sales. Put simply, customers don't want to be sold to. They want credible content in a coherent order, before speaking to a consultative salesperson who actually wants to help the prospect and not just sell to them to achieve their quota.

So, here is the key point - only when technology that supports this model is put in place can those of you on the content strategy production line ever be successful. At the very least, marketers need to think about the

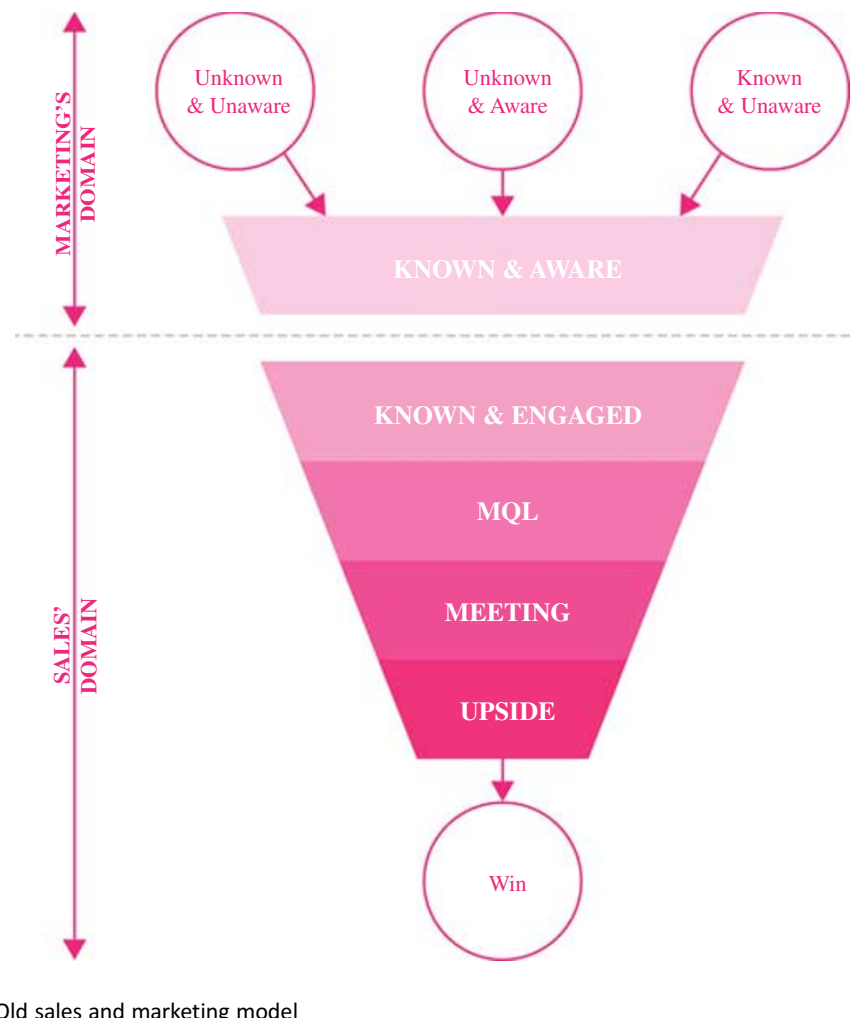




\section{Buying on knowledge}

\section{Technology supports marketing's ambitions}

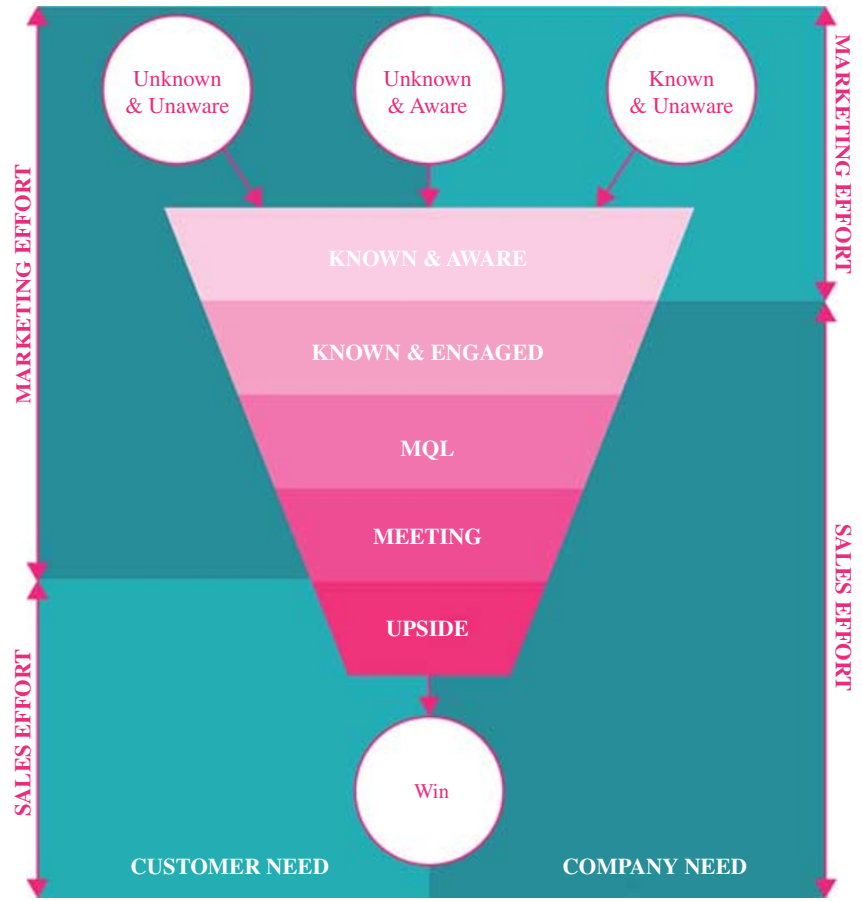

Figure 3: Customer-focused sales and marketing mode

integration of a content management system (for web design), marketing automation for campaign management and analytics, and a customer relationship management system for sales- and account-based selling and marketing (see Figure 4).

Research by Forrester ${ }^{1}$ and $\mathrm{CEB}^{2}$ reveals that in two-thirds of situations, customers don't buy on a feature set of functions - the 'bells and whistles' - unless the market the vendor operates in is very commodity-based. Instead, customers buy from companies where knowledgeable, consultative representatives take the time to educate them, to de-risk the decision-making journey, and to challenge their current thinking and long-held views. So, coherent content is important here to extend through the buying stages in a logical manner.

\section{What this means for marketing}

There are three areas in which marketing technology will reshape your organization:

1. It means marketing has an opportunity to increase its influence inside the organization by driving a coherent technology strategy that maps content to match each customer's buying cycle, not the company's sales cycle (which is still essential, but is a smaller stage in the overall cycle).

2. It means that marketing representatives need to replace sales representatives in the early stages of dialogue as the genuine voice of the customer, using technology to unearth valuable audience insights that the leadership team can action. 


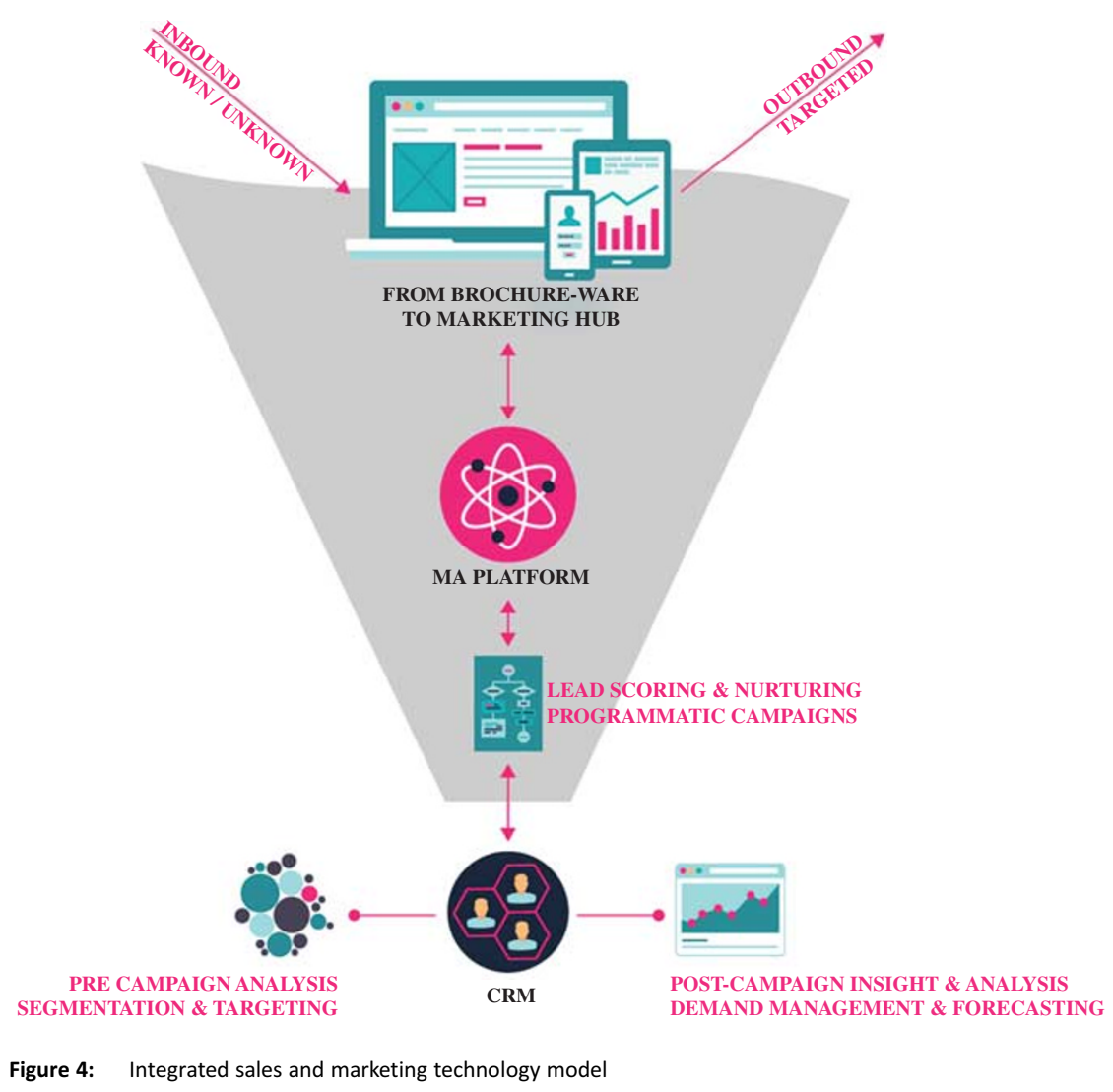

Socialising technology

3. It means that marketing must embrace this new thinking and take it to the leadership team in a way for which sales doesn't have time and won't risk cannibalizing its own position of influence, and in a manner that the IT function simply can't communicate.

If you are curious, ambitious and industrious (after all, you are a marketer, so you should be), then my final recommendation is to think big. Create a vision for what a coherent marketing technology strategy and architecture could look like and take new thinking back to the business. Part of this bigger thinking has to involve technology taking a central role in your strategy and for you to socialize its impact around the business. On the basis that every business is a digital business, surely this is so much more important than any content strategy alone?

\section{References}

1. Ramos, L. (2013) 'B2B marketing measurement needs to sharpen its business acumen', http:// blogs.forrester.com/laura_ramos/13-09-03-b2b_marketing_measurement_needs_to_sharpen_its_ business_acumen.

2. CEB Marketing Leadership Council (in partnership with Google). (2012) 'The digital evolution in B2B marketing'. http://www.executiveboard.com/exbd-resources/content/digital-evolution/pdf/ Digital-Evolution-in-B2B-Marketing.pdf. 